\title{
Neutron Detector Gamma Insensitivity Criteria
}

\author{
RT Kouzes \\ JR Ely \\ AT Lintereur \\ DL Stephens
}

October 28, 2009

\section{Pacific Northwest}




\title{
DISCLAIMER
}

This report was prepared as an account of work sponsored by an agency of the United States Government. Neither the United States Government nor any agency thereof, nor Battelle Memorial Institute, nor any of their employees, makes any warranty, express or implied, or assumes any legal liability or responsibility for the accuracy, completeness, or usefulness of any information, apparatus, product, or process disclosed, or represents that its use would not infringe privately owned rights. Reference herein to any specific commercial product, process, or service by trade name, trademark, manufacturer, or otherwise does not necessarily constitute or imply its endorsement, recommendation, or favoring by the United States Government or any agency thereof, or Battelle Memorial Institute. The views and opinions of authors expressed herein do not necessarily state or reflect those of the United States Government or any agency thereof.

\author{
PACIFIC NORTHWEST NATIONAL LABORATORY \\ operated by \\ BATTELLE \\ for the \\ UNITED STATES DEPARTMENT OF ENERGY \\ under Contract DE-AC05-76RL01830
}


PNNL-18903

\title{
Neutron Detector Gamma Insensitivity Criteria
}

\author{
RT Kouzes \\ JR Ely \\ AT Lintereur \\ DL Stephens
}

October 28, 2009

Pacific Northwest National Laboratory

Richland, Washington 99352 


\section{Executive Summary}

The shortage of ${ }^{3} \mathrm{He}$ has triggered the search for an effective alternative neutron detection technology for radiation portal monitor applications. Any new detection technology must satisfy two basic criteria: 1) it must meet the neutron detection efficiency requirement, and 2) it must be insensitive to gamma-ray interference at a prescribed level, while still meeting the neutron detection requirement. It is the purpose of this document to define this latter criterion.

It is required that a neutron detector for homeland security applications in radiation portal monitors not produce any alarms when exposed to a $10 \mathrm{mR} / \mathrm{h}$ gamma-ray exposure rate. Additionally, three quantitative requirements are specified with minimum values that are:

1) Absolute neutron detection efficiency, $\epsilon_{\mathrm{abs}} \geq 2.5 \mathrm{cps} / \mathrm{ng}{ }^{252} \mathrm{Cf}$ at $2 \mathrm{~m}$ for a source in a defined moderated form

2) Intrinsic gamma-neutron detection efficiency, $\epsilon_{\text {int } \gamma \mathrm{n}} \leq 10^{-6}$

3) Gamma absolute rejection ratio for neutrons, $0.9 \leq \mathrm{GARRn} \leq 1.1$ at $10 \mathrm{mR} / \mathrm{h}$ exposure

An example of results from a ${ }^{3} \mathrm{He}$ based neutron detector are provided showing that this technology can meet these requirements. Results from other technologies will be reported separately. 


\section{Acronyms and Abbreviations}

ANSI

cps

DOE

GARRn

PNNL

PVT

RPM

RSP

SAIC
American National Standards Institute

counts per second

U.S. Department of Energy

gamma absolute rejection ratio for neutrons

Pacific Northwest National Laboratory

Polyvinyl Toluene (plastic) scintillation gamma detector

Radiation Portal Monitor

Radiation Sensor Panel

Science Applications International Corporation 


\section{Contents}

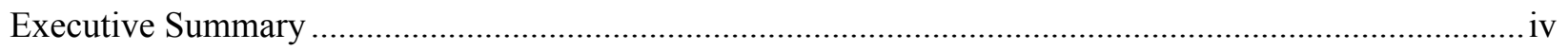

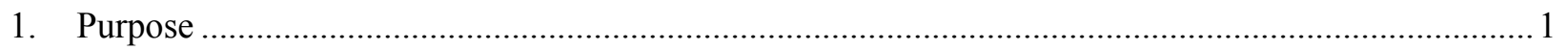

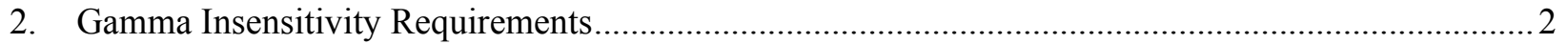

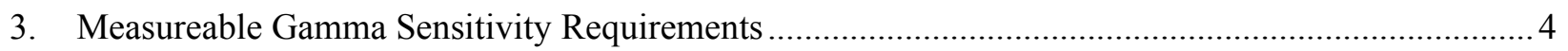

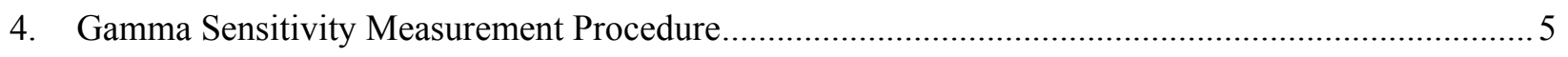

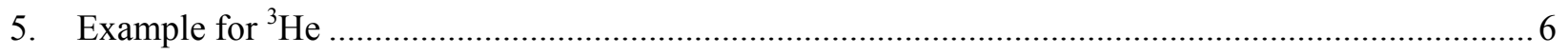

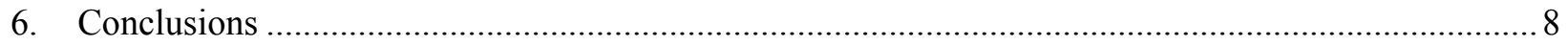

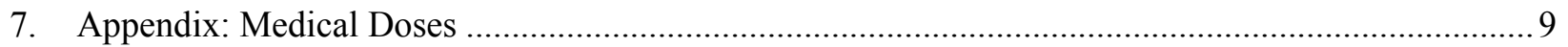

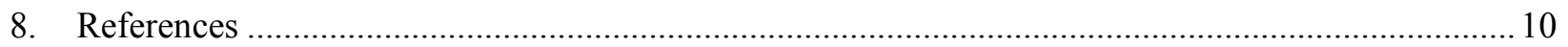




\section{Figures and Tables}

\section{Figures}

Figure 5.1. Moderator box containing a ${ }^{3} \mathrm{He}$ tube positioned between neutron ${ }^{60} \mathrm{Co}$ sources................... 6

Figure 5.2. Spectra from a ${ }^{3} \mathrm{He}$ tube in the presence of ${ }^{60} \mathrm{Co}$ and neutron sources (expanded in Figure 5.3)

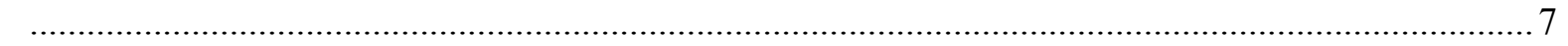

Figure 5.3. Spectra from a ${ }^{3} \mathrm{He}$ tube in the presence of ${ }^{60} \mathrm{Co}$ and neutron sources.................................... 7

\section{Tables}

Table 2.1. Requirements for gamma insensitivity of neutron detectors................................................ 2

Table 5.1. Results from ${ }^{3} \mathrm{He}$ measurements ................................................................................ 7

Table 7.1. Selected medical and commercial source doses from PNNL report (Siciliano 2004) and

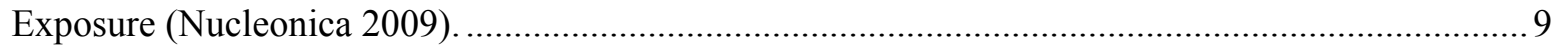




\section{Purpose}

Radiation portal monitor (RPM) systems utilize neutron detectors for the potential interdiction of plutonium (Kouzes 2008). These detectors have traditionally been based on ${ }^{3} \mathrm{He}$ proportional counters, which have high neutron detection efficiency and very low sensitivity to gamma ray interference. The shortage of ${ }^{3} \mathrm{He}$ has triggered a search for an effective alternative neutron detection technology for RPMs (Kouzes 2009; Van Ginhoven et al. 2009). Any new detection technology must satisfy two basic criteria: 1) it must meet the neutron detection efficiency requirement, and 2) it must be insensitive to gamma ray interference at a prescribed level, while still meeting the neutron detection requirement. It is the purpose of this document to define this latter criterion.

For purposes of this document, a standard Science Application International Corporation (SAIC) RPM8 radiation sensor panel (RSP) is used as the mechanical and performance reference. The criteria discussed in this document are of potential use for any RPM system.

For reference, the required neutron detection efficiency as stated in the procurement specification for the Radiation Portal Monitoring Project (RPMP) is for the detector in a single RSP to have an absolute efficiency of 2.5 counts per second per nanogram of ${ }^{252} \mathrm{Cf}$ for a moderated source $(0.5 \mathrm{~cm}$ of lead, $2.5 \mathrm{~cm}$ of polyethylene) located at $2 \mathrm{~m}$ from the center face of the detector (Stromswold 2003). The nanograms in this requirement are equivalent nanograms of ${ }^{252} \mathrm{Cf}$ for the aged source. This requirement is met for the RPM systems currently in deployment. Advanced spectroscopic portal monitors (ASP) have a requirement that is somewhat more stringent, exceeding the $2.5 \mathrm{cps} / \mathrm{ng}$.

Deployed RPM systems that use polyvinyl toluene (PVT) based gamma ray detectors are required to meet all aspects of the ANSI N42.35 standard (ANSI 2006), while spectrometric portal monitors must meet the requirements of ANSI N42.38 (ANSI 2007). A summary of neutron detection systems in RPMs can be found in a Pacific Northwest National Laboratory (PNNL) report (Kouzes et al. 2007). 


\section{Gamma Insensitivity Requirements}

There are three documents from which the requirements for gamma ray insensitivity of neutron detectors used in PVT-based RPM systems can be obtained (Stromswold 2003; ANSI 2006; IAEA 2008). The requirements for gamma ray insensitivity of neutron detectors from these sources are listed in Table 2.1.

Table 2.1. Requirements for gamma insensitivity of neutron detectors.

\begin{tabular}{|l|l|}
\hline Source Document & \multicolumn{1}{c|}{ Requirement } \\
\hline $\begin{array}{l}\text { RPMP } \\
\text { (Stromswold 2003) }\end{array}$ & $\begin{array}{l}\text { The neutron detector shall not generate alarms due to the presence of strong } \\
\text { gamma-ray sources. The ratio of neutron sensor's gamma-ray detection efficiency } \\
\text { to neutron detection shall be less than } 0.001\end{array}$ \\
\hline $\begin{array}{l}\text { American National } \\
\text { Standards Institute } \\
\text { ANSI N42.35 } \\
\text { (ANSI 2006) }\end{array}$ & $\begin{array}{l}\text { Gamma radiation at exposure rates of up to } 10 \mathrm{mR} / \mathrm{h} \text { (at the face of the center of the } \\
\text { detection assembly) shall not trigger the neutron alarm. (T\&E Protocol: Using }{ }^{137} \mathrm{Cs}, \\
\text { increase the ambient gamma-ray exposure rate by } 10 \mathrm{mR} / \mathrm{h} \text { as measured at the center of the } \\
\text { surface of the detection assembly while the monitor is occupied. Remove the radiation } \\
\text { source and allow the monitor to return to normal operation and repeat the test for a total of } \\
3 \text { trials. Immunity of neutron detectors to gamma radiation is confirmed if no neutron } \\
\text { alarms are triggered. }\end{array}$ \\
\hline $\begin{array}{l}\text { International } \\
\text { Atomic Energy } \\
\text { Agency } \\
\text { Specification } \\
\text { (IAEA 2008) }\end{array}$ & $\begin{array}{l}\text { The vehicle monitor }[\mathrm{RPM}] \text { must not trigger a neutron alarm when exposed to a } \\
{ }^{60} \text { Co gamma ray source producing a dose rate at the reference point of the neutron } \\
\text { detectors of } 100 \mu \mathrm{Sv} \cdot \mathrm{h}^{-1}( \pm 30 \%)\left[10 \mathrm{mrem} \cdot \mathrm{h}^{-1}\right]\end{array}$ \\
\hline
\end{tabular}

These requirements are of limited usefulness for purposes of defining an actual performance criterion for gamma insensitivity, since they simply require thresholds to be set such that no alarms occur. These requirements also do not specify the simultaneous use of a neutron source. ${ }^{1}$ Thus, the requirements can be met with zero neutron detection efficiency during gamma ray exposure. A more quantitative measure of gamma ray rejection would be of value. The RPMP specification (Stromswold 2003) required ${ }^{3} \mathrm{He}$ tubes be used. These tubes have excellent gamma ray insensitivity, assuming appropriate electronics and settings are used. The requirement applies more to the discrimination system in the detector electronics than the neutron detection system. The ANSI N42.35 standard is intended as a minimum performance requirement for systems. The IAEA specification assumes a reasonable detection threshold has been set.

Currently deployed ${ }^{3} \mathrm{He}$-based neutron detection systems under the RPMP meet or exceed a gamma discrimination ratio of 0.0001 up to an exposure rate of $100 \mathrm{mR} / \mathrm{h}$ with a ${ }^{60} \mathrm{Co} \gamma$ tested as defined in ANSI 42.35 (ANSI 2006). This is the approximate exposure limit of performance for ${ }^{3} \mathrm{He}$-based neutron detector systems.

The required exposure rate in which a neutron detector must perform is most conveniently defined in terms of the largest source to which it might be exposed in commerce. Medical sources are one class of large sources that are seen. The Appendix lists typical medical sources and exposure rates for an administered radionuclide in a person. It is seen in Table 7.1 that the largest exposure at $1 \mathrm{~m}$ expected

\footnotetext{
${ }^{1}$ The latest IEC standard for spectroscopic portals includes a requirement: Gamma radiation at an ambient dose equivalent rate of up to $100 \mu \mathrm{Sv} \cdot \mathrm{h}^{-1}$ (at the face of the detection assembly) shall not trigger the neutron alarm. The presence of the ambient gamma dose equivalent rate used for test shall not prevent the neutron alarm from activating when exposed simultaneously to the neutron source and the gamma source.
} 
from U.S. radiopharmaceuticals is $\sim 10 \mathrm{mR} / \mathrm{h}$ at the time of injection. Larger doses have been observed. For the purpose of setting criteria for gamma ray insensitivity, the exposure rate of $10 \mathrm{mR} / \mathrm{h}$ will be used for consistency with the standards and specification. It can be noted that this exposure level could be increased without impacting tests performed to date.

A time period must be defined for measurements. Since as many as $\sim 100,000$ people cross at a single crossing each day, $10^{6}$ measurements will be assumed as the criterion without an alarm.

It is thus reasonable to extrapolate a dose rate to be used for testing neutron detectors:

It is required that a neutron detector for homeland security applications in RPMs not produce any neutron alarms when exposed to a $10 \mathrm{mR} / \mathrm{h}$ gamma-ray exposure rate during $10^{6}$ measurements, while still meeting the neutron detection requirement. 


\section{Measureable Gamma Sensitivity Requirements}

It is highly desirable that quantified, measurable criteria be specified for the gamma ray insensitivity requirement of neutron detectors for RPM applications. Three criteria are proposed here that are used to completely specify acceptable performance of a neutron detection system for use in a RPM:

1) Absolute neutron detection efficiency, $\epsilon_{\mathrm{abs} n}$

2) Intrinsic gamma-neutron detection efficiency, $\epsilon_{\text {int } \gamma \mathrm{n}}$

3) Gamma absolute rejection ratio for neutrons, GARRn.

The absolute neutron detection efficiency $\left(\epsilon_{\mathrm{abs} n}\right)$ defines the required efficiency for neutron detection in a specific geometry. The intrinsic gamma-neutron detection efficiency $\left(\epsilon_{\mathrm{in} t} \mathrm{n}\right)$ for gamma rays detected as neutrons indicates the gamma-neutron separation, and GARRn, defined below, specify the gammaneutron separation simultaneously with the required neutron efficiency.

The first criterion is measured with only a neutron source present. The RPMP specification requires that $\mathbf{C}_{\text {abs n }}=\mathbf{2 . 5} \mathrm{cps} / \mathbf{n g}^{252} \mathrm{Cf}$ at $2 \mathrm{~m}$ for a source in a defined moderated form (Stromswold et al 2003). The absolute efficiency $\left(\epsilon_{\text {abs }}\right)$ is the number of pulses recorded per number of radiation quanta emitted by a source in a specific geometry (Knoll 1999, p. 116).

For the second and third criteria, it is assumed that a large gamma ray source is present to uniformly expose the detector. A ${ }^{192} \mathrm{Ir},{ }^{137} \mathrm{Cs}$, or ${ }^{60} \mathrm{Co}$ source is chosen as the gamma ray source. At a given exposure rate, these sources provide the same number of photons onto the neutron detector within a factor of $\sim 3$ (refer to Table 7.1). This is because of the difference in photons energy from the two sources, but in practice there is little difference between measurements. The ${ }^{60} \mathrm{Co}$ source is preferred because it is used in the ANSI N42.38 standard.

The intrinsic efficiency $\left(\epsilon_{\text {int }}\right)$ is the number of pulses recorded per number of radiation quanta striking the detector (Knoll 1999, p. 116). Variation in this parameter is expected between alternative neutron detection solutions. The gamma-neutron intrinsic efficiency $\left(\epsilon_{\text {int } \gamma \mathrm{n}}\right)$ specifically measures the response of a neutron detector to the presence of a gamma ray field when no neutron source is present. It is the net number of "neutron" detections divided by the number of photons striking the detector.

At an exposure rate of $10 \mathrm{mR} / \mathrm{h}, \epsilon_{\text {int } \gamma \mathrm{n}}$ should be very small for a well-behaved neutron detector (such as it is for a ${ }^{3} \mathrm{He}$ detector with an appropriate threshold ${ }^{2}$ ), on the order of $10^{-7}$ or better. For well-designed ${ }^{3} \mathrm{He}$ proportional counter-based neutron detectors, the ratio can be $\leq 10^{-5}$ for gamma ray exposure rates up to $100 \mathrm{mR} / \mathrm{h}$ (NRC 1991, pp. 380-391). Thus, it is reasonable to specify that $\boldsymbol{\epsilon}_{\mathrm{int} \gamma \mathbf{n}} \leq \mathbf{1 0}^{-6}$ at $10 \mathrm{mR} / \mathrm{h}$.

The "gamma absolute rejection ratio for neutrons" (GARRn) is defined by PNNL in this document. This parameter measures the detector response in the presence of both a large gamma ray source and a ${ }^{252} \mathrm{Cf}$ neutron source (configured as it would be for an absolute efficiency measurement). The GARRn is defined as the absolute neutron detection efficiency $\left(\epsilon_{\mathrm{abs} \gamma \mathrm{n}}\right)$ in the presence of both sources, divided by the absolute neutron detection efficiency $\left(\epsilon_{\text {abs n }}\right)$ of the neutron detector:

$$
\operatorname{GARRn}=\epsilon_{\mathrm{abs} \gamma \mathrm{n}} / \epsilon_{\mathrm{abs} \mathrm{n}}
$$

The value of this ratio would be 1 if the gamma ray source had no impact. The proposed GARRn specification is: $0.9<$ GARRn $<1.1$ at $10 \mathrm{mR} / \mathrm{h}$ exposures.

A $10 \%$ limitation on GARRn has been chosen since an increase of $10 \%$ in this value will not generally produce false neutron alarms for operational systems, and a $10 \%$ decrease is within other uncertainties of deployment of a typical system (such as lane width, weather variations, diurnal variability,...) .

\footnotetext{
${ }^{2}$ The threshold referenced here is typically either a hardware or software pulse height discriminator used to distinguish the smaller pulses produced by gamma rays and other noise from the larger pulses produced by neutrons.
} 


\section{Gamma Sensitivity Measurement Procedure}

It is proposed that the following procedure be used to test the gamma ray sensitivity of a neutron detector and determine whether it is acceptable technology. All measurements shall be performed such that counting statistics are not the limiting uncertainty in the measurements.

1. The neutron background rate shall be measured and used in the subsequent measurements to determine net counts.

2. A moderated $\sim 20 \mu \mathrm{Ci}\left(37 \mathrm{ng}\right.$ ) ${ }^{252} \mathrm{Cf}$ source (in $5 \mathrm{~mm}$ of lead and $25 \mathrm{~mm}$ of polyethylene) shall be placed $2 \mathrm{~m}$ from the center of the neutron detector face. The absolute neutron efficiency $\epsilon_{\mathrm{abs} n}$ shall be measured cps/ng, with no added gamma ray source present. The neutron detection efficiency requirement shall be met by the detector system before proceeding to determination of the gamma ray insensitivity requirement.

3. $\mathrm{A}^{192} \mathrm{Ir}$ or ${ }^{60} \mathrm{Co}$ source shall be placed at an appropriate distance so as to produce an exposure rate of $10 \mathrm{mR} / \mathrm{h}$ at the detector with no neutron source present. The $\epsilon_{\text {int }}$ vn value shall be determined.

4. $\mathrm{A}{ }^{192} \mathrm{Ir}$ or ${ }^{60} \mathrm{Co}$ source shall be placed at an appropriate distance so as to produce a uniform exposure rate of $10 \mathrm{mR} / \mathrm{h}$ across the detector face, and the same neutron source shall be placed at $2 \mathrm{~m}$ as above. The GARRn value shall be determined.

All three criteria ( $\epsilon_{\mathrm{abs} n}, \epsilon_{\mathrm{int}} \mathrm{n}_{\mathrm{n}}$, and GARRn), as described previously, must be met for the neutron detector to meet the neutron detection requirements. 


\section{Example for ${ }^{3} \mathrm{He}$}

As an example of the application of the criteria defined here, consider a single 3 -atmosphere ${ }^{3} \mathrm{He}$ tube in a moderator box of dimensions $127 \mathrm{~mm}$ deep $\times 305 \mathrm{~mm}$ wide $\times 2.177 \mathrm{~m}$ long $\left(5^{\prime \prime}\right.$ deep $\times 12^{\prime \prime}$ wide $\times 85.7$ " long). Figure 5.1 shows this detector placed $2 \mathrm{~m}$ from a neutron source (foreground) and at a distance from a ${ }^{60} \mathrm{Co}$ source (tube in center of ring in the background) to produce a $10 \mathrm{mR} / \mathrm{h}$ exposure rate.

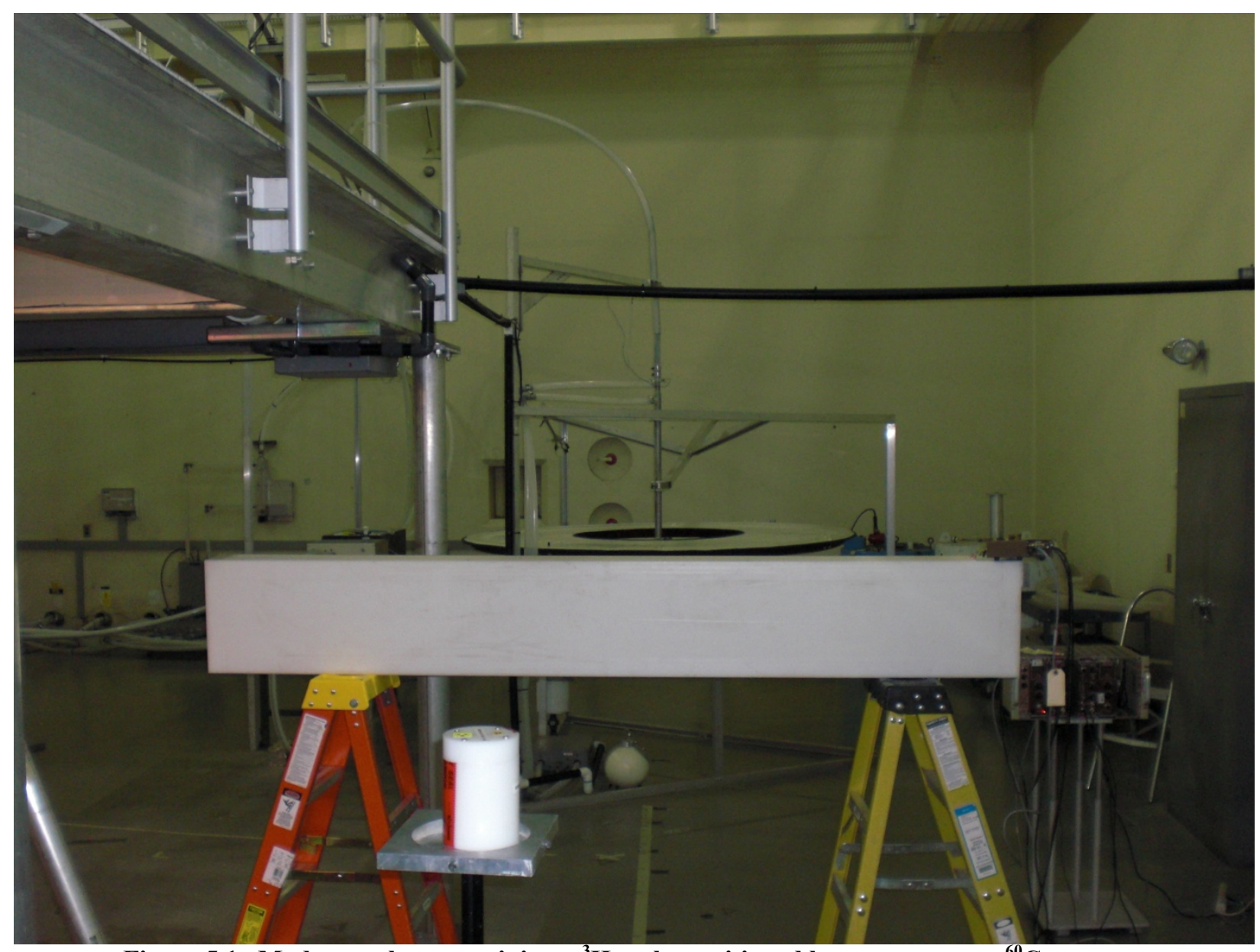

Figure 5.1. Moderator box containing a ${ }^{3} \mathrm{He}$ tube positioned between neutron ${ }^{60} \mathrm{Co}$ sources

Measurements were made of the absolute neutron detection efficiency, the intrinsic gamma-neutron detection efficiency, and GARRn for this detector. The absolute neutron detection efficiency was measured on both the front side and the backside of the moderator box for convenience in performing the gamma ray measurements. Figures 5.2 and 5.3 show the response of the detector in the presence of both ${ }^{60} \mathrm{Co}$ and neutron sources, with different vertical scales. Figure 5.2 shows the full gamma ray induced peak, while Figure 5.3 is scaled to show the neutron response.

The results (Table 5.1) show that the ${ }^{3} \mathrm{He}$ tube meets all three criteria for an acceptable neutron detector as defined in this document. It should be noted that this testing only included the neutron detector and did not include the associated electronics in an integrated RPM system. Testing of the integrated system must be performed before that system is acceptable for homeland security applications. 


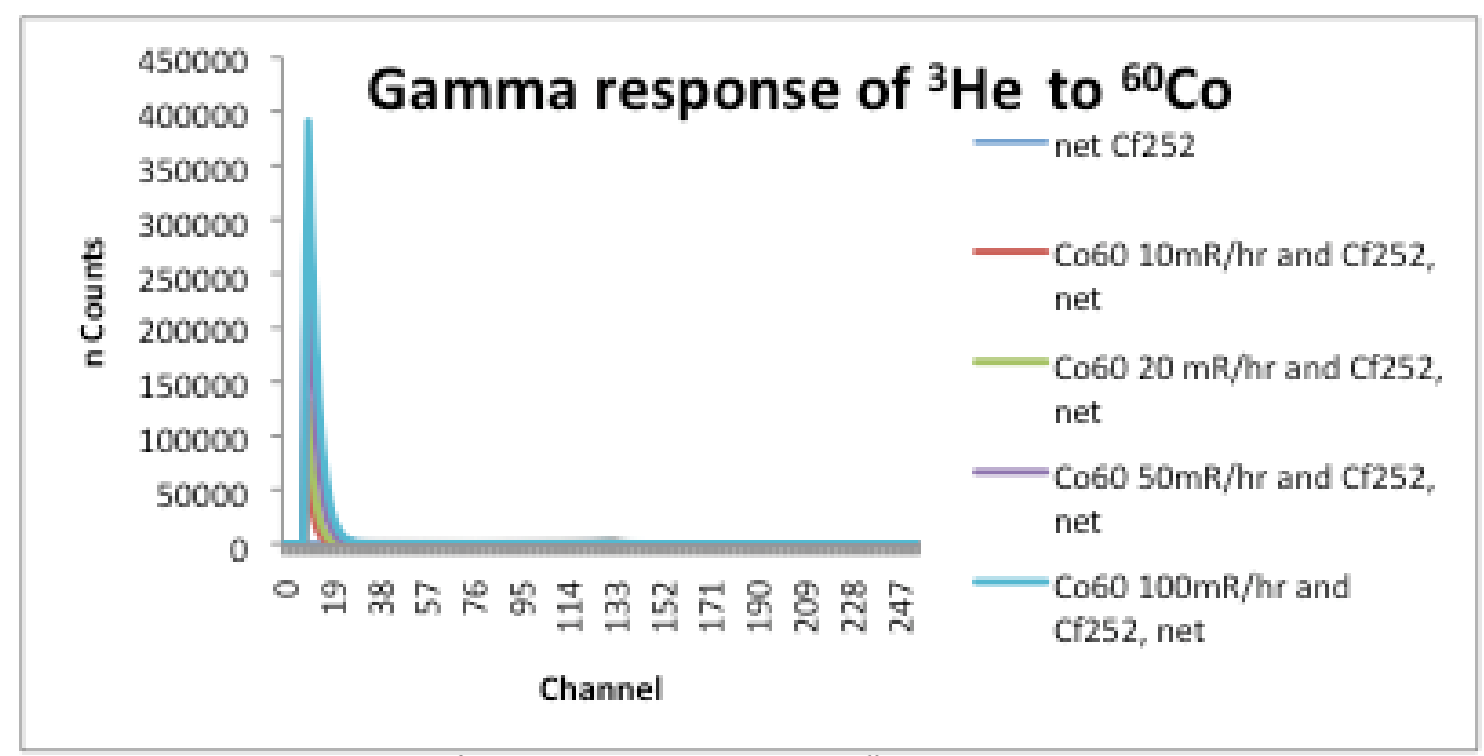

Figure 5.2. Spectra from a ${ }^{3} \mathrm{He}$ tube in the presence of ${ }^{60} \mathrm{Co}$ and neutron sources (expanded in Figure 5.3)

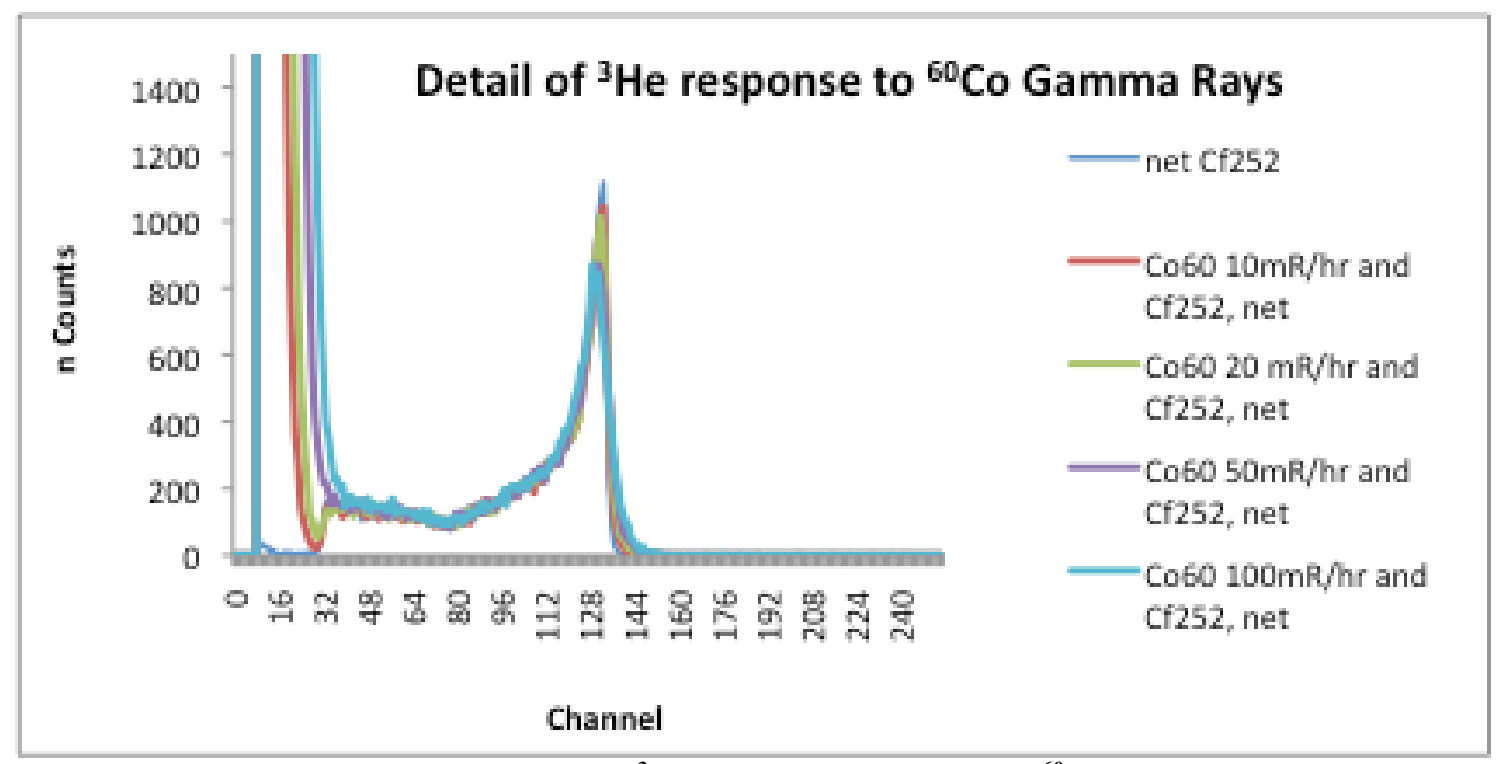

Figure 5.3. Spectra from a ${ }^{3} \mathrm{He}$ tube in the presence of ${ }^{60} \mathrm{Co}$ and neutron sources

Table 5.1. Results from ${ }^{3} \mathrm{He}$ measurements

\begin{tabular}{|l|l|l|}
\hline \multicolumn{1}{|c|}{ Parameter } & \multicolumn{1}{c|}{ Value } & \multicolumn{1}{c|}{ Requirement } \\
\hline$\epsilon_{\text {abs } n}$ front & $2.83 \mathrm{cps} / \mathrm{ng}$ & $\geq 2.5 \mathrm{cps} / \mathrm{ng}$ \\
\hline$\epsilon_{\text {abs } \mathrm{n}}$ back & $2.24 \mathrm{cps} / \mathrm{ng}$ & - \\
\hline$\epsilon_{\text {int }}$ $\mathrm{nn}$ at $10 \mathrm{mR} / \mathrm{h}$ & $1.7 \times 10^{-9}$ & $\leq 10^{-6}$ \\
\hline GARRn at $10 \mathrm{mR} / \mathrm{h}$ & 0.99 & $0.9 \leq \mathrm{GARRn} \leq 1.1$ \\
\hline
\end{tabular}




\section{Conclusions}

A measurement method has been defined to determine the gamma ray insensitivity of neutron detectors and specifications have been proposed for accepting or rejecting a neutron detector system. The proposed performance specifications are:
1) $\mathbf{\epsilon}_{\mathbf{a b s} \mathrm{n}} \geq \mathbf{2 . 5} \mathrm{cps} / \mathrm{ng}{ }^{252} \mathrm{C}$ f at $2 \mathrm{~m}$ for a source in a defined moderated form
2) $\epsilon_{\text {int } \gamma \mathrm{n}} \leq 10^{-6}$
3) $\mathbf{0 . 9} \leq$ GARRn $\leq \mathbf{1 . 1}$ at $10 \mathrm{mR} / \mathrm{h}$ exposures

The testing of a neutron detector system for homeland security applications should be performed as an integrated system configured for deployment to be sure that the system as a whole performs as specified here. 


\section{Appendix: Medical Doses}

Table 7.1 lists common medical isotopes and their average administered activity and halflife. The conversion to exposure (X) for $r>0$ is given approximately by (Knoll 2002):

$$
\mathrm{X}=\mathrm{Ga} / \mathrm{r}^{2}
$$

The exposure is given in $\mathrm{mR} / \mathrm{h}$ at $1 \mathrm{~m}$. The worst case is $\sim 10 \mathrm{mR} / \mathrm{h}$, with ${ }^{99 \mathrm{~m}} \mathrm{Tc}$ being $\sim 1 \mathrm{mR} / \mathrm{h}$.

Table 7.1. Selected medical and commercial source doses from PNNL report (Siciliano 2004) and Exposure (Nucleonica 2009).

\begin{tabular}{|l|c|c|c|c|c||}
\hline Isotope & $\begin{array}{c}\text { Average } \\
\text { Administered } \\
\text { Activity (MBq) }\end{array}$ & $\begin{array}{c}\text { Average } \\
\text { Administered } \\
\text { Activity (mCi) }\end{array}$ & Half Life & $\begin{array}{c}\text { Conversion to } \\
\text { Exposure (G) } \\
\text { R/h @ 1 } \\
\text { from 1 Ci } \\
\text { Source }\end{array}$ & $\begin{array}{c}\text { Exposure (X) } \\
\text { mR/h at 1 m }\end{array}$ \\
\hline C-14 & 0.0370 & $1.0 \times 10^{-3}$ & $5700 \mathrm{y}$ & 0 & - \\
\hline Co-57 & 0.0222 & $6 \times 10^{-4}$ & $270 \mathrm{~d}$ & 0.054 & $3 \times 10^{-5}$ \\
\hline Co-60 & - & & $5.27 \mathrm{y}$ & 1.26 & \\
\hline Cr-51 & 2.775 & 0.075 & $27.7 \mathrm{~d}$ & 0.017 & 0.0013 \\
\hline F-18 & 740.0 & 20 & $109 \mathrm{~min}$ & 0.55 & 11 \\
\hline Ga-67 & 370.0 & 10 & $78 \mathrm{~h}$ & 0.077 & 0.77 \\
\hline In-111 & 119.33 & 3.2 & $68 \mathrm{~h}$ & 0.31 & 1.00 \\
\hline $\mathrm{I}-123$ & 11.10 & 0.3 & $13.3 \mathrm{~h}$ & 0.15 & 0.05 \\
\hline I-131 & 1546.7 & 42 & $8 \mathrm{~d}$ & 0.21 & 8.8 \\
\hline Sm-153 & 5180.0 & 140 & $46.8 \mathrm{~h}$ & 0.044 & 6.2 \\
\hline Sr-89 & 148.0 & 4 & $50.5 \mathrm{~d}$ & $4.6 \times 10^{-5}$ & $2 \times 10^{-4}$ \\
\hline Tc-99m & 625.71 & 16.9 & $6 \mathrm{~h}$ & 0.074 & 1.25 \\
\hline Ba-133 & & & $10.55 \mathrm{y}$ & 0.29 & \\
\hline Cs-137 & & & $30 \mathrm{y}$ & 0.16 & \\
\hline Ir-192 & & & $2400 \mathrm{y}$ & 0.44 & \\
\hline Tl-201 & 740.00 & 20 & $73.5 \mathrm{~h}$ & 0.044 & 0.88 \\
\hline
\end{tabular}




\section{References}

ANSI. 2006. American National Standard for Evaluation and Performance of Radiation Detection Portal Monitors for Use in Homeland Security. Technical Report. ANSI 42.35, American Nuclear Standards Institute, Washington, D.C.

ANSI. 2007. American National Standard Performance Criteria for Spectroscopy-Based Portal Monitors Used for Homeland Security. Technical Report. ANSI 42.35, American Nuclear Standards Institute, Washington, D.C.

IAEA 2008. Technical and Functional Specifications for Border Monitoring Equipment. IAEA Nuclear Security Series No. 1 Technical Guidance, Vienna, Austria.

Knoll GF. 2002. Radiation Detection and Measurement $3^{\text {rd }}$ Ed. John Wiley and Sons, New York.

Kouzes, RT, JH Ely, PE Keller, RJ McConn, and ER Siciliano. 2008. "Passive Neutron Detection for Interdiction of Nuclear Material at Borders." Nuclear Instruments and Methods in Physics Research Section A: Accelerators, Spectrometers, Detectors and Associated Equipment 584(2-3): 383-400.

Kouzes RT, J Ely, and E Siciliano. 2007. Neutron Alarm Algorithms for Deployed RPMs. PIET-43741TM-663, PNNL-17101, Pacific Northwest National Laboratory, Richland, Washington.

Kouzes, RT. 2009. “The ${ }^{3}$ He Supply Problem," Pacific Northwest National Laboratory Report PNNL18388 .

Siciliano, ER. 2004. Medical Radioisotope Data Survey: 2002 Preliminary Results. PNNL report PIET43741-TM-197, PNNL-14882.

Stromswold D, J Ely, R Kouzes, J Schweppe. 2003. Specifications for Radiation Portal Monitor Systems Revision 6.7. PIET-43741-TM-017, Pacific Northwest National Laboratory, Richland, Washington.

Van Ginhoven, RM, RT Kouzes, DL Stephens, 2009. “Alternative Neutron Detector Technologies for Homeland Security,” Pacific Northwest National Laboratory Report PNNL-18471. 


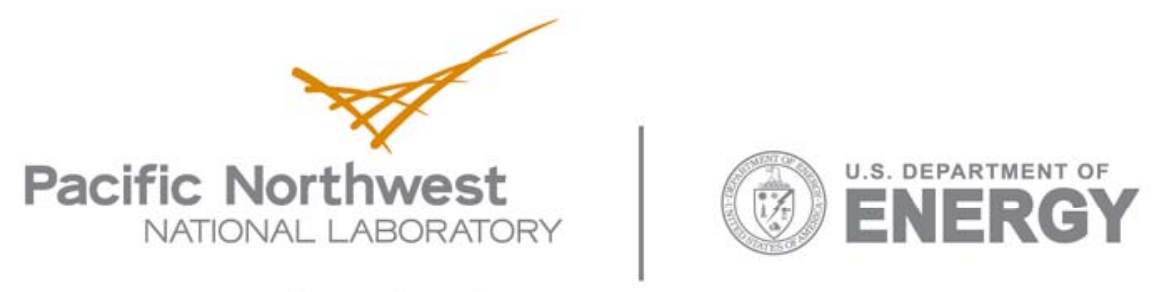

902 Battelle Boulevard

P.O. Box 999

Richland, WA 99352

1-888-375-PNNL (7665)

www.pnl.gov 